\title{
A CRISE POLÍTICA DO NEODESENVOLVIMENTISMO E A INSTABILIDADE DA DEMOCRACIA*
}

\author{
Armando Boito $\mathrm{Jr}^{* *}$
}

\begin{abstract}
Resumo: $O$ artigo sustenta que a crise política atual é uma crise da política neodesenvolvimentista e que ela foi provocada, fundamentalmente, pela ofensiva restauradora do campo político neoliberal ortodoxo, e não pelo ascenso do movimento popular. Mostra também que a crise da política neodesenvolvimentista convive com uma situação de instabilidade do presidencialismo autoritário e da democracia.
\end{abstract}

Palavras-chave: crise política, neodesenvolvimentismo, governo Dilma, PT, impeachment.

\begin{abstract}
This article argues that the current political crisis is a crisis of neodevelopmentism policy and that it was brought primarily by the offensive of the orthodox neoliberal political field, not by the rise of the popular movement. It also shows that the crisis of developmentism policy coexists with a situation of instability of the authoritarian presidential system and democracy.
\end{abstract}

Keywords: political crisis, neo-developmentism, Dilma government, PT, impeachment.

\section{A crise política}

A crise política atual é a crise do governo neodesenvolvimentista de Dilma Rousseff. Exacerbaram-se contradições já presentes no processo político brasileiro, surgiram contradições novas e consolidou-se uma força política organizada com capacidade para depor o governo. Essa crise foi provocada, fundamentalmente, pela forte ofensiva restauradora do campo neoliberal ortodoxo que pretende iniciar uma nova onda de reformas neoliberais no Brasil (Saad-Filho e Boito, 2016). Esse ponto é importante: a crise não foi provocada pela luta operária e popular. Embora essa luta seja um componente importante da crise política, ela está longe de ser o seu componente

\footnotetext{
* Artigo redigido em novembro de 2015 e publicado na revista Crítica Marxista número 42, maio de 2016. Pp. 155-163.

** Professor do Departamento de Ciência Política da Unicamp. Email: armando.boito@gmail.com
} 
principal. Apenas o campo neoliberal ortodoxo adquiriu condições de ocupar o poder governamental no caso de ocorrer a deposição da presidente.

O campo neodesenvolvimentista e o campo neoliberal ortodoxo não são agrupamentos com composição social aleatória e que teriam como principal fator de coesão a crença em doutrinas econômicas rivais. A aplicação da plataforma neodesenvolvimentista contempla prioritariamente os interesses da grande burguesia interna, enquanto a aplicação das propostas neoliberais contempla as demandas do capital internacional e da fração da burguesia brasileira a ele integrada. Cada uma dessas grandes frações burguesas arregimentou aliados nas classes dominadas. A política neodesenvolvimentista da grande burguesia interna contempla, de maneira periférica, algumas reivindicações de segmentos do operariado, da baixa classe média, de trabalhadores rurais da agricultura familiar e de trabalhadores da massa marginal, segmentos com os quais formou uma frente política policlassista, ampla, heterogênea e contraditória que denomino frente neodesenvolvimentista. Essa frente disputa com o campo formado pelo grande capital internacional, pela fração da burguesia brasileira integrada a esse capital e pela fração superior da classe média, que é o campo neoliberal ortodoxo, o controle da política econômica, da política social e da política externa do Estado brasileiro (Boito, 2012; Boito e Berringer, 2013). Os governos apoiados no PT representam o campo neodesenvolvimentista, do mesmo modo que os governos apoiados no PSDB representaram o campo neoliberal ortodoxo.

A crise política atual está abalando essa divisão de campos que prevaleceu no período recente da política brasileira. A linha divisória entre, de um lado, as classes e frações de classe alinhadas no campo neodesenvolvimentista e, de outro, as classes e frações alinhadas no campo neoliberal ortodoxo, que nunca foi uma linha reta e rígida, tornou-se, com a crise, sinuosa e maleável e essa mudança se deu de modo a aumentar a força do campo neoliberal ortodoxo. No topo da frente neodesenvolvimentista, sempre se mantivera aceso o conflito entre o capital bancário nacional e o capital produtivo nacional; no conjunto da frente, também permanecera ativo o conflito entre as reivindicações das massas trabalhadoras - salário, direitos trabalhistas, terra - e os interesses de variados segmentos da grande burguesia interna. Contudo, até há pouco, a unidade da frente neodesenvolvimentista vinha prevalecendo claramente sobre os seus conflitos internos. Na crise, essa unidade se encontra minada.

Não se pense, convém alertar, que o outro campo está livre de contradições. A alta classe média acomoda-se com alguma dificuldade na frente neoliberal ortodoxa. A 
política fiscal ortodoxa, que caracteriza o neoliberalismo puro e duro, golpeia também a alta classe média - de maneira imediata golpeia o alto funcionalismo público, segmento importante dessa fração de classe. Do mesmo modo que ocorreu com a inserção das classes populares na frente política neodesenvolvimentista, a inserção da alta classe média no campo neoliberal ortodoxo deu-se, em boa medida, pelas características da conjuntura ideológica e pelas exigências da correlação política de forças.

Contudo, foram as contradições internas da frente neodesenvolvimentista que se exacerbaram na crise, enquanto o campo neoliberal ortodoxo preservou a sua unidade e ganhou novos adeptos. De fato, como resultado da degradação da situação econômica, cuja responsabilidade pode, independentemente de consideração de mérito, ser atribuída ao governo do momento; como resultado da ofensiva restauradora do capital internacional e como resultado, também, do recuo da política econômica e social do governo Dilma Rousseff, segmentos do topo e da base do campo neodesenvolvimentista passaram a oscilar politicamente, foram neutralizados ou se bandearam para o lado do campo neoliberal ortodoxo. Importantes associações corporativas da grande burguesia interna - Fiesp, Sinaval, Abdib, Abimaq, Abiquim e outras - assumem uma posição ambígua: chegam a admitir a necessidade de algum ajuste fiscal mas, ao mesmo tempo, protestam contra as medidas de ajuste; setores importantes do movimento sindical, como a central Força Sindical, ao mesmo tempo em que protestam contra o ajuste aproximam-se da oposição neoliberal; no Congresso, partidos que compunham a base de apoio do governo dividiram-se ou bandearam-se para a oposição. A sustentação do governo Dilma Rousseff ficou comprometida.

\section{A ofensiva burguesa neoliberal}

Alguns analistas da política brasileira destacaram que o primeiro biênio do primeiro mandato de Dilma Rousseff caracterizou-se por uma ofensiva da política neodesenvolvimentista. André Singer dedicou a essa ofensiva um estudo recente e instrutivo (Singer, 2015). O governo Dilma não eliminou os pilares do modelo capitalista neoliberal que impedem a implantação de uma política desenvolvimentista estrito senso, mas, como o seu predecessor, tomou medidas visando a atenuar os efeitos negativos desse modelo sobre o crescimento econômico. De fato, os anos de 2011 e 2012 ficaram marcados, na política econômica e social, por medidas visando, por intermédio da intervenção do Estado na economia, estimular o crescimento econômico 
- redução da Selic, do spread, desvalorização do real, ampliação da política de conteúdo local, isenções fiscais para capital produtivo e outras. O então Ministro da Fazenda, Guido Mantega, resumiu essa nova orientação cunhando a expressão "nova matriz de política econômica".

Parece-nos possível sustentar a tese de que essa nova matriz representava não apenas uma radicalização da política neodesenvolvimentista, mas também uma alteração no interior dessa política. Era a tentativa de beneficiar o segmento produtivo da grande burguesia interna em detrimento dos interesses do seu segmento bancário. Ou seja, essa política aprofundou um conflito que sempre esteve presente na grande burguesia interna e, ao mesmo tempo, despertou a reação do capital internacional e da fração da burguesia brasileira a ele integrada. Foram essas forças que iniciaram uma ofensiva contra o Governo Dilma no início de 2013. As agências internacionais, as agências de avaliação de risco, a imprensa conservadora da Europa e dos Estados Unidos, a grande mídia local, os partidos burgueses de oposição ao governo, a alta classe média e algumas das instituições do Estado que abrigam esse segmento social entraram na luta contra a política do Ministro da Fazenda. Grande parte dessa luta concentrou-se na denúncia superlativa da inflação e no ataque à corrupção na Petrobras, isto é, tratou de agitar bandeiras que pudessem contar com algum apoio popular.

\subsection{A participação da alta classe média}

Um capítulo importante da ofensiva política restauradora e da crise que dela resultou é a ação política da alta classe média.

Em primeiro lugar, essa ação tem propiciado uma ampla e ativa base de massa para a ofensiva restauradora da burguesia internacionalizada. Centenas de milhares de manifestantes mobilizaram-se nas principais cidades do país em fevereiro, março, abril e agosto de 2015. Os protestos convergiram para a demanda de impeachment da presidente Dilma. Ocorreram, também, inúmeros "panelaços". Todas as informações disponíveis sobre tais ações de protestos comprovam que eles são, de forma amplamente majoritária, ações da classe média abastada. Tais ações não são controladas pela burguesia internacionalizada e, justamente por isso, entretêm uma relação difícil com a direção do PSDB; elas funcionam, contudo, como principal instrumento de legitimação da ofensiva burguesa restauradora. 
Em segundo lugar, a alta classe média age, também, por intermédio de importantes instituições do Estado contra o partido do governo e contra o próprio governo neodesenvolvimentista. A alta classe média dispõe de uma posição estratégica no Judiciário, no Ministério Público e na Polícia Federal. Os funcionários que ocupam a cúpula dessas instituições - juízes, procuradores, desembargadores, defensores públicos, delegados e outros - gozam de salários e de condições de trabalho inigualáveis no setor público brasileiro. Ademais, temos de considerar a função de tais instituições no seio do Estado. Elas representam aquilo que Pierre Bourdieu (1998) denominou "a mão direita" do Estado. Isto é, o ramo do Estado incumbido de manter a lei e a ordem capitalista. Seja por seu pertencimento de classe, seja por sua alocação nesse ramo da burocracia do Estado, os funcionários que dirigem tais instituições assumem uma posição militante contra a política social do neodesenvolvimentismo. $\mathrm{O}$ PT, como tem ocorrido com os partidos de perfil socialdemocrata, enveredou para a prática do nepotismo e da corrupção, principalmente voltada para o financiamento privado e ilegal das campanhas eleitorais e para a conquista de apoio no Congresso. Os altos funcionários do Ministério Público, da Polícia Federal e do Judiciário valem-se dessa prática corrupta para, de maneira unilateral, denunciar, investigar e julgar quase que exclusivamente as práticas de corrupção cometidas pelo PT e pelos seus aliados.

É certo que os governos neodesenvolvimentistas reabriram os concursos públicos, ampliaram a autonomia do Ministério Público e não agiram contra os privilégios de nenhum desses funcionários. Porém, os principais aspectos da política social do neodesenvolvimentismo ferem interesses econômicos e valores do conjunto da alta classe média, tanto do setor público quanto do setor privado, e são percebidos como uma ameaça por esse setor social. Os programas de transferência de renda para a população em situação precária, as quotas raciais e sociais nas universidades e no serviço público, a extensão dos direitos trabalhistas às empregadas e empregados domésticos, a recuperação do salário mínimo, essas e outras medidas são vistas pela alta classe média como uma conta que ela deverá pagar por intermédio dos impostos que lhe são cobrados, como uma ameaça à reserva de mercado que os seus filhos ainda detêm nos cursos mais cobiçados das grandes universidades e nos cargos superiores do serviço público, como afrontas aos valores da ideologia meritocrática - tão cara aos profissionais com diploma universitário -, como uma intromissão nas relações autoritárias e paternalistas que as famílias de classe média mantêm com os seus funcionários domésticos e como medidas indesejáveis por possibilitar que espaços e 
instituições anteriormente reservados à alta classe média fossem "invadidos" por indivíduos pertencentes aos setores populares.

A política de ordem dos governos petistas também incomoda a alta classe média. Ela está aquém da dureza que delegados, procuradores e juízes gostariam, como funcionários da ordem, que fosse implementada. Os governos Lula da Silva e Dilma Rousseff mantiveram a ordem capitalista e a repressão à luta popular. Ocorre que, na comparação com a política repressiva dos governos do campo neoliberal ortodoxo, a política de ordem dos governos do PT aparece, aos olhos da alta classe média, como uma política demasiado tolerante.

\subsection{A presença das classes trabalhadoras}

A luta popular também contribuiu para o surgimento da crise, mas desempenhou um papel secundário se comparado ao papel da ofensiva neoliberal restauradora. Para utilizarmos a conceituação conhecida de Mao Zedong, a contradição principal que determinou a crise foi a que opõe o conjunto do campo neoliberal ortodoxo frente à política neodesenvolvimentista. A contradição entre as classes trabalhadoras e a burguesia participou da crise na condição de contradição secundária - não porque dissesse respeito a disputas de menor importância para a vida de milhões de brasileiros, mas exatamente porque a luta operária e popular é, ainda, uma luta reivindicativa e segmentada.

A ofensiva neoliberal restauradora iniciou-se antes das manifestações de junho de 2013 e, ao contrário dessas últimas, sempre teve clareza política e força suficiente para eleger como alvo a conquista do poder governamental, de tal modo que, após breve hesitação inicial, a ofensiva restauradora do campo neoliberal ortodoxo passou a estimular as manifestações de rua de modo a canalizá-las para o objetivo de derrotar eleitoralmente o governo Dilma. A heterogeneidade e a acefalia política das manifestações facilitaram esse trabalho da reação. Em 2014, ano da eleição presidencial, a grande imprensa passou a estimular novamente as manifestações, direcionando-as, agora, contra a Copa do Mundo de Futebol - posição que, muito sintomaticamente, a imprensa não assume neste ano de 2015 diante de evento similar que é a Olimpíada do Rio de Janeiro. As manifestações de junho de 2013 são um componente da crise por terem afastado grande parte da baixa classe média - que fora 
beneficiada pela forte expansão do ensino universitário promovida pelo neodesenvolvimentismo - do próprio governo neodesenvolvimentista. De fato, as pesquisas indicam que nessas manifestações predominavam jovens, com ensino superior e renda média ou baixa, decepcionados com o emprego de baixa qualidade que a economia lhes oferecia a despeito de eles terem obtido um diploma de curso superior (Ridenti, 2013).

O movimento sindical cresceu muito no período da política neodesenvolvimentista. Dois indicadores bem simples atestam a veracidade dessa afirmação: se em 2003, ocorreram cerca de 300 greves, dez anos depois, graças a um crescimento gradativo e regular, os trabalhadores atingiram a marca de mais de 2.000 greves no ano; se também, no ano de 2003, apenas 18\% dos acordos e convenções coletivas chegaram a obter aumento real de salário, dez anos depois, nada menos que 95\% desses acordos e convenções obtiveram aumento acima da inflação. Esse assenso, contudo, não representou um crescimento político do movimento sindical. A luta manteve-se no plano estritamente reivindicativo e segmentada por categorias. As conquistas sindicais, ao aumentarem os custos salariais das empresas, não foram bem recebidas pela grande burguesia interna, porém não há indícios de que tais conquistas tenham implodido a frente política neodesenvolvimentista. O que ocorreu claramente foi a defecção de parte do sindicalismo da frente neodesenvolvimentista. A insatisfação no movimento sindical proveio do fato de o neodesenvolvimentismo ter ignorado demandas históricas do movimento sindical - redução da jornada semanal de trabalho para 40 horas, regulamentação restrita da terceirização, fim do fator previdenciário e outras. Majoritariamente, essa defecção foi atraída pelo campo neoliberal ortodoxo.

\section{A instabilidade da democracia}

A crise do governo está associada a uma situação de instabilidade do presidencialismo brasileiro e da própria democracia burguesa vigente no Brasil.

A situação de instabilidade, tal qual a situação de crise, caracteriza-se pelo surgimento de obstáculos importantes na reprodução de uma dada estrutura ou instituição política - um Estado, um regime político ou um governo -, mas, diferentemente do que ocorre numa situação de crise, na situação de instabilidade não há uma força política organizada capaz de e disposta a substituir a instituição cuja 
reprodução mostra-se claudicante por outra que ocupe o seu lugar. A situação de instabilidade está aquém da situação de crise.

O Executivo Federal, no regime que poderíamos denominar presidencialista autoritário, controla a atividade legislativa (Torre, 1996; Saes, 2001). Esse controle deixou de existir desde a derrota do governo Dilma na eleição para a presidência da Câmara dos Deputados. Tal instabilidade institucional está vinculada à ofensiva restauradora do campo neoliberal ortodoxo, mas é algo mais que a sua mera faceta institucional. A insubmissão do Congresso Nacional é promovida, evidentemente, pelas forças neoliberais, mas também pela resistência ao ajuste fiscal e pela guerra declarada pela bancada evangélica e conservadora contra os movimentos feminista e LGBT.

Presenciamos, ainda, uma situação de instabilidade da democracia burguesa vigente no Brasil. Essa é uma democracia limitada. Já nos referimos ao presidencialismo autoritário que esvazia a função legislativa e representativa do Congresso Nacional. Caberia acrescentar a precariedade das liberdades democráticas: inexistência de liberdade de organização sindical, aparelhos repressivos do Estado e mesmo milícias privadas agindo por conta própria contra a população trabalhadora nos bairros populares e nas regiões rurais e a existência de uma mídia extremamente concentrada e desregulamentada. A instabilidade dessa democracia é visível numa conjuntura em que presenciamos sucessivas tentativas de revogar o veredicto dado pelas urnas em outubro de 2014. São ações com argumentos, trâmites e instâncias os mais diversos, cujos únicos pontos em comum residem no desprezo pela regra democrática da vontade da maioria e no objetivo de depor o governo. Tais ações indicam o desapego da oposição burguesa às instituições e aos valores democráticos. Ainda não há uma crise da democracia porque, até aqui, a proposta de implantação de um regime ditatorial é muito minoritária no campo oposicionista, situação que difere da conjuntura em que se deu o golpe militar de 1964.

\section{A reação do governo e o movimento popular}

Diante da ofensiva política restauradora das forças que integram o campo neoliberal ortodoxo, o governo Dilma Rousseff optou por uma política de recuo e não de resistência. Aplica o ajuste fiscal, que é parte importante do programa da oposição 
burguesa neoliberal, e não toma a iniciativa de mobilizar os setores populares sequer para defender o próprio mandato.

Nessa situação, o campo socialista e popular tem, em primeiro lugar, de travar uma luta defensiva. Essa luta comporta dois objetivos cuja relação é complexa e pode se tornar contraditória. É preciso, de um lado, resistir à política de ajuste fiscal do governo e, de outro, defender a democracia e, portanto, o mandato que o governo conquistou nas urnas. Se, temendo favorecer a reação, decidir manter-se neutro diante do ajuste, estará abrindo mão da defesa de interesses elementares das classes populares; se, alegando o recuo conservador do governo Dilma, se propuser a lutar, aqui e agora, pela constituição de um poder popular, produzirá como único resultado prático, dada a atual correlação de forças, o avanço da reação. É certo, contudo, que a política de defesa do mandato tem limite. Se o governo mantiver a orientação de se defender do processo de impedimento apenas no âmbito das instituições do Estado e se mantiver a política de ajuste fiscal, a defesa do mandato da presidente poderá se ver comprometida.

Em segundo lugar, o campo socialista e popular precisa apresentar a sua proposta para a situação de instabilidade que afeta a democracia limitada e o presidencialismo autoritário vigentes no Brasil. É necessário propagandear e agitar uma proposta que aponte para uma ofensiva. A palavra-de-ordem da Constituinte exclusiva e soberana para a reforma do sistema político pode ser a resposta que, se vitoriosa, poderá permitir o aprofundamento da democracia no Brasil, desbloqueando o caminho para as reformas exigidas pelo movimento popular.

\section{Referências bibliográficas}

BOITO Jr., Armando. As bases políticas do neodesenvolvimentismo. Fórum Econômico da

FGV-SP. 2012.< $<$ http://eesp.fgv.br/sites/eesp.fgv.br/files/file/Painel\%203\%20$\% 20$ Novo $\% 20$ Desenv $\% 20$ BR $\% 20-\% 20$ Boito $\% 20$ \%20Bases\%20Pol\%20Neodesenv\%20-\%20PAPER.pdf $>$

BOITO Jr., Armando e BERRINGER, Tatiana. "Brasil: classes sociais, neodesenvolvimentismo e política externa nos governos Lula e Dilma. Revista de Sociologia e Política, no.47. pp. 94-109. 2013

BOURDIEU, Pierre. Contre-feux. Propos pour servir à la résistance contre l'invasion néoliberale. Paris, Raisons d'Agir, 1998.

RIDENTI, Marcelo. Que juventude é essa?. Folha de S. Paulo, 26 de junho de 2013. 
SAAD-FILHO, Alfredo e BOITO, Armando. Brazil: The Failure of the PT and the Rise of the 'New Right'. Socialist Register, v. 52, pp. 213-230. 2016. $<$ http://socialistregister.com/index.php/srv/article/view/25598\#.VjPAt7erQdU>.

SAES, Décio. A política neoliberal e o campo político conservador no Brasil atual. In: Décio Saes, República do capital. Capitalismo e processo político no Brasil. São Paulo: Boitempo. 2001.

SINGER, André. Cutucando onças com varas curtas - o ensaio desenvolvimentista no primeiro mandato de Dilma Rousseff (2011-2014). Novos Estudos Cebrap, n. 102. Pp. 43-71. 2015.

TORRE, Juan Carlo. O encaminhamento político das reformas estruturais. Lua Nova, n. 37. Pp. 65-82. 1996. 